\title{
EL MUNDO AYMARA Y VAN KESSEL *
}

JGV: ¿Cuándo le nace el interés por estudiar la cultura aymara o la cultura andina en general?

JVK: En los años sesenta me interesé por los peregrinajes a los santuarios populares del norte de Chile (Las Peñas, La Tirana, Aiquina) donde hay bailes religiosos que, al analizarlos, mellevaron automáticamente a las raíces andinas de la religiosidad católica.

JGV: Este acercamiento ¿tiene que ver con su formación teológica o filosófica?

JVK: Tiene que ver con mi actividad previa al año 1963 en la pastoral parroquial y en la pastoral social en tiempo de Salvador Allende, donde toda la atención se volcaba a la gente más necesitada, y no sólo a sus condiciones materiales, sociales y económicas, sino también a sus expresiones culturales y religiosas que،se podían observar en los santuarios populares, cuando lloraban y suplicaban a la Virgen que les ayudara en sus problemas particulares.

\section{JGV: ¿Cómo se inicia su acercamiento a lo andino?}

JVK: En los santuarios no sólo se ven danzas y bailarines, también se mira otro tipo de población: los "llameros" que bajan de la Cordillera a vender carne a los que vienen de la ciudad. Allí había dos grupos concentrados alrededor del santuario, $y$, en algún momento, me tocó intermediar para conseguir carne por los bailes religiosos. Esto fue muy casual, pero me hice muyamigo de una gente de la comunidad de Tirima, ubicada a $4200 \mathrm{~m}$ de altura, quienes posteriormente, me pidieron que les haga el servicio de bautizarles una iglesia que se les había quemado, debido a la caída de un rayo.

\section{JGV:¿Casualidad o mensaje de la Virgen?}

JVK: La historia es que un curandero interpretó este

\footnotetext{
- Juan van Kessel (Eindhoven-Holanda, 1934). Ha vivido en el norte de Chile desde 1960, realizando diversas investigaciones sobre religiosidad popular, tecnologia y cultura andino - aymaras. Cuenta con estudios en teología, antropologia y filosofía. Ha sido entre 1972-1975, catedrático en universidades del norte de Chile y desde 1977 es docente e investigador de la Facultad de Antropología Cultural de la Universidad Libre de Amsterdam - Holanda. En junio de 1995, visitó Tacna -invitado por la organización Wiñaya Aymara Marka- para dictar una conferencia sobre cultura aymara. En una frigida e invernal banca de la plaza Quiñonez, José Gabriel Valdivia realizó la presente entrevista.
}

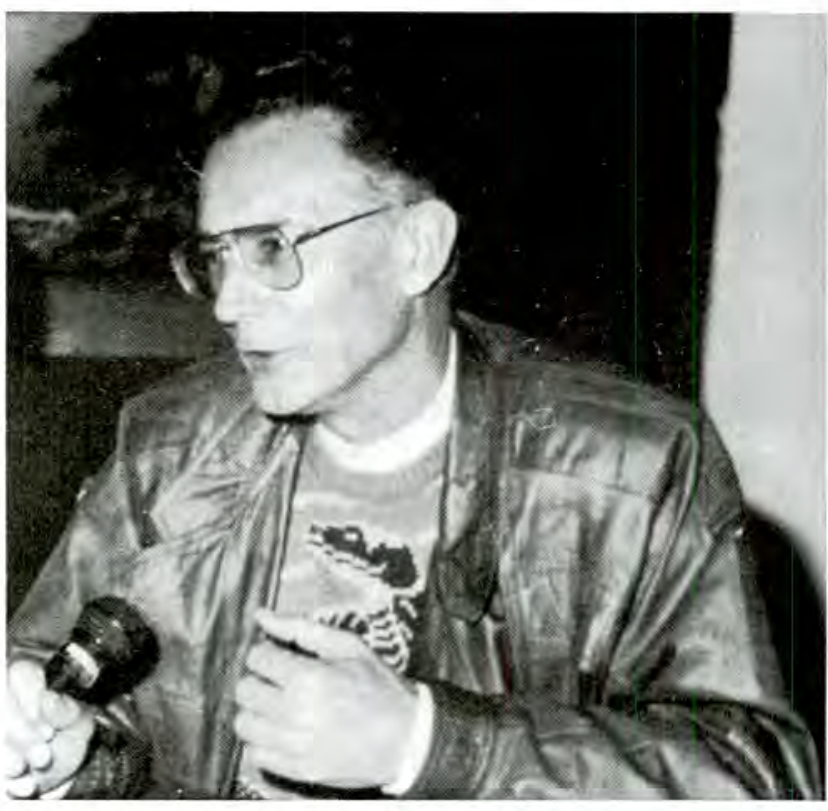

hecho como un castigo de San Santiago contra el pueblo, entonces, la comunidad hizo un gran esfuerzo para reconstuir el templo con faenas, ayunos y oraciones. Era necesario bendecirlo y hacer una gran fiesta. Pero a este pueblo no había llegado un cura en los últimos quince años, así que me pidieron que fuera.

Era muy lejos Tirima, pero llegue, después de andar, casi todas las distancias, a pie. Cuando estuve allí, un dos de febrero-día de la Candelariacayó una lluvia grande y no hubo cómo entrar en la Cordillera. Ocurrieron inundaciones, caminos cortados y no pudimos volver. Entonces, me quedé un mes observando, conviviendo y participando en todos los cultos y trabajos de la comunidad.

Así comenzó todo, producto de una gran amistad y de una necesidad del pueblo. También, de mi interés personal, pues ya tenía estudios de Antropología.

JGV: Se volvió un peregrino europeo en tierras andinas

JVK: Así es. Puedo decir un peregrino que ha aprendido mucho y que realmente me siento muy enriquecido por mis maestros andinos -por muy sencillos que 
fueran-, por su mitologia, su cultura, su religiosidad. Realmente, uno puede apreciar mejor lo que uno tiene y lo que ellos tienen, con la única condición de observar los valores andinos sin prejucio alguno.

JGV: ¿Dentro de lo andino lo aymara o lo quechua es fundamental?

JVK: Fundamentales son ambos. Lo andino incluye lo aymara y lo quechua. Así lo tomo yo. No es el tiempo del Inca, porque se ha ido evolucionando con impactos fuertes, traumatizantes, enriquecedores y con muchas influencias históricas.

Ninguna cultura del mundo queda estable, siempre está en vías de cambio. La cultura andina, quechua o aymara, es una cultura con gran capacidad empática, que se la conoce participando, y que tiene una inmensa riqueza para aportar a la construcción del Perú en un futuro próximo.

Sólo en la parte ecológica, ellos tienen escritas en el alma, las preocupaciones ecologistas modernas. En muchas partes del Perú actual, todavía no se tiene conciencia de ello, y van a tener que tomar conciencia de los daños que se pueden hacer en la ecología, si no se cuida la Tierra como lo han hecho, desde siempre, los andinos.

JGV: ¿Qué elementos culturales le impresionan más en su estudio de lo aymara?

JVK: Lo que más me impresiona son algunos principios de su cosmovisión. Un principio es que todo tiene vida: los animales, la chacra, los cerros, la santa tierra, todo es personificado y tiene vida. El ser humano es uno más que participa en la vida universal que nos llega a través de la "pachamama", la madre universal. Uno puede estar dialogando, alternando, reciprocando con la madre tierra y con todo el medio natural y con todo lo que hace. De modo que su trabajo es una manera de interacción recíproca. No como en Occidente, donde importa lo que yo estoy trabajando y el resto es materia disponible, sin que haya unarelación recíproca. En el mundo andino siempre se está dialogando, considerando la naturaleza humana y la naturaleza no humana.

JGV: ¿Ambas naturalezas son iguales, se equilibren o se necesitan?

JVK: En el fondo, somos diferentes de las llamas, de los cerros y de todas las cosas, pero de alguna manera, somos connaturales, participamos de la universalidad de la vida.

De alli que se puede dar una condición de persona a la tierra (madre tierra) o a los cerros "achachilas". Cuando ya son personas, se puede dialogar y dialogando uno les tiene mucho más respeto, ya no son materia disponible que uno puede agarrar y hacer lo que quiera, incluso destruirla. Eso nunca puede suceder en el mundo andino.

JGV: ¿Le temen a la naturaleza o simplemente la respetan?

JVK: En el momento que en el mundo andino se produce un aborto, incluso involuntario, pero voluntario de todas maneras, sus miembros se preocupan, porque después viene el castigo en forma de granizada. Entonces piensan y dicen: si yo no respeto la vida, por este aborto cometido, la vida no me respeta a mí y vienen los tres hermanos: granizada, helada y viento a destruir la vida en $\mathrm{mi}$ chacra, aplastando los cultivos. Ahí se da un paralelismo entre to humano y lo no humano, gracias a un profundo respeto por la vida.

El principio ético básico de los andinos es un profundo respeto a la vida: he ahí su principal mandamiento.

JGV: En su conferencia Ud. mencionó otros principios.

La complementariedad es otro aspecto que me impresiona. El ser humano nunca es el último, el individuo nunca es el último núcleo de la sociedad, de la comunidad o del ayllu: la familia es el último núcleo de la comunidad. En Occidente, el individuo tiene su número de carnet de identidad para la administración pública. En el mundo andino, el individuo sólo está completo cuando se casa y ya es una familia. La familia es el último eslabón de la sociedad.

JGV: ¿Este hombre aymara mantiene o practica esos principios?

Los mantiene, pero con vergüenza. En momentos de crisis los activa, los respeta. En ese momento, hay una especie de renacimiento de conciencia de la identidad andina. En el norte de Chile, muchos jóvenes que han sido "culturizados", se presentan ante las autoridades con mucha franqueza, reclamándose aymaras, indigenas. Antes no, se escondian diciendo: no soy de ahí, no entiendo aymara.

Es que ahora, por múltiples razones (como es el caso de la guerra última entre Perú y Ecuador, donde muchos indígenas han caído en combate y se les ha declarado héroes) se sienten tomados en cuenta por la sociedad circundante, entonces se presentan como tales y reclaman su identidad con orgullo. 
Los aymaras en Tacna, creo, que están camuflados y no quieren darse a conocer, pero de repente pueden presentarse vestidos de poncho rojo y llenar toda la plaza.

JGV: ¿Con qué visión occidental, Ud. llega a observar el mundo andino aymara. Cuál es la que tiene ahora?

JVK: En un principio, nos lo enseñaron como un pueblo de un granpasado, pero de unas condiciones materiales y espirituales muy deterioradas y que necesitaban de mucho apoyo para sacarlos de su idolatría.

Ahora es diferente. Como profesor de Sociología del Desarrollo en la Universidad de Amsterdam, enfoco el problema, no cómodamente sentado desde un sillón holandés, sino desde mis experiencias con las víctimas del desarrollo, porque desarrollo y subdesarrollo están muy relacionados. Alli he aprendido que el subdesarrollo es un producto del desarrollo capitalista, y que el mundo andino no es subdesarrollado por naturaleza, sino porque se ha hecho subdesarrollado.

En tiempos de los incas eran desarrollados, igual o más que los conquistadores españoles de la época. Pero éstos los tomaron como primitivos, idólatras, etcétera, rebajándolos en su nivel de vida y desapareciéndolos en las guerras, en las minas o con enfermedades.

JGV: En la actualidad, ¿existen serios conflictos culturales en esta zona?

JVK: Sí. En mi estudio hecho en el norte de Chile, he observado conflictos entre los aymaras y los de la ciudad, a través de los bailes religiosos que se presentan en el santuario de Las Peñas y la fiesta de La Tirana. Esto también se notaba, hace 20 ó 25 años atrás, en las procesiones parroquiales, cuando se discutía fuertemente por la participación de unos o la no participación de otros grupos de baile.

Esto lo explicábamos -en la época- como una forma de la lucha de clases. Pero no, todos eran obreros salitreros y sindicalistas. En el fondo, lo que existía era un conflicto entre grupos culturales. De un lado, la cultura religiosa popular contra la religiosidad oficialista de la iglesia católica - la de los protestantes. Un pueblo organizándose en asociaciones de bailes bajo la bandera de su devoción a la Virgen, un pueblo anticlerical, comunista o socialista, pero con su propia religiosidad.

JGV: ¿Es un problema para los aymaras estar disgregados en cuatro nacionalidades?
JVK: De todas maneras sí. Esta división política fue hecha hace 170 años y con afanes de separar y controlar a los indígenas que eran numerosos y que habian formado parte de la insurrección de Tupac Amaru II. Por eso, los criollos, temerosos, los separaron para que piensen primero en su bandera nacional y no en la lealtad a sus hermanos de raza. Ahora, también se pretende bolivianizar, chilenizar o peruanizar a los aymaras.

JGV: ¿Qué está estudiando actualmente?

JVK: La tecnología andina como base del desarrollo autosostenido, emancipatorio, que no cree dependencias. No una tecnología foránea, sino una tecnología enriquecida por los elementos de afuera, pero basada en la tecnología propia.

Y cual es lo particular. Primero, ellos conocen su medio, el clima, la tierra, sus recursos naturales, la calidad del agua por sus contenidos minerales y la forma de su uso. Ellos son los que mejor pueden realizar el desarrollo agropecuario de la Cordillera. Y no lo hacen sólo con conocimientos empíricos, sino que agregan algo que, en la modernidad, los ingenieros no lo aprecian, y es lo que llamamos tecnología simbólica, a través de los rituales de producción como son: el pago a la tierra, lasformas de homenaje a las cruces (en el mes de mayo), el floreo para el ganado y todas las actividades religiosas simbólicas que sirven para estimular, de una u otra manera, el proceso de producción.

La tecnología andina tiene dos elementos: lo empírico y lo simbólico. Si se la moderniza hay que tener en cuenta ello que, además, tiene un contenido ecológico que los occidentales han olvidado.

JGV: ¿La visión moderna de lo que es desarrollo contempla esos dos aspectos?

JVK: Los contempla, poquito a poco, pero aún está lejos. Los grandes empresarios siempre saben justificar que están sacando millones de toneladas de agua, en zonas semiáridas, para la minería. Ellos están construyendo la minería a costa del medio natural y del sector agropecuario. Así pasa, al menos, en el norte de Chile, y siempre tienen argumentos, porque necesitamos más puestos de trabajo, porque el país necesita divisas, etc. Es muy necesario que se cree una conciencia ecologista, pues los indígenas, aymaras y quechuas, son los más llamados a dar este mensaje al Perú, Bolivia y Chile del siglo XXI, porque ellos respetan la Tierra como su madre, nunca matan a la madre. 